PINELI, L.L.O.; MORETTI,C.L.; ALMEIDA, G.C.; NASCIMENTO, A.B.G.; ONUKI, A.C.A. Associação de atmosfera modificada e antioxidantes reduz o escurecimento de batatas 'Ágata' minimamente processadas. Horticultura Brasileira, Brasília, v.23, n.4, p.993-999, out-dez 2005.

\title{
Associação de atmosfera modificada e antioxidantes reduz o escurecimento de batatas 'Ágata' minimamente processadas
}

\author{
Lívia L.O. Pineli ${ }^{1}$; Celso L. Moretti ${ }^{2}$; Gustavo C. Almeida ${ }^{3}$; Aline B.G. Nascimento ${ }^{4}$; Ana Cecília A. Onuki ${ }^{4}$ \\ ${ }^{2}$ Embrapa Hortaliças, C. Postal 218, 70359-970 Brasília-DF; E mail: celso@ cnph.embrapa.br; ${ }^{3}$ UFLA, 37200-000 Lavras-MG; ${ }^{4}$ Faculda- \\ de da Terra de Brasília, 72610-300 Brasília-DF; ' Programa de Mestrado do Depto. Nutrição da UnB, 70910-900 Brasília-DF
}

\begin{abstract}
RESUMO
O escurecimento enzimático da batata minimamente processada reduz o valor comercial do produto. O objetivo deste trabalho foi avaliar alterações químicas e físicas em batatas 'Ágata' minimamente processadas embaladas sob atmosfera modificada em associação com antioxidantes. Batatas 'Ágata' foram minimamente processadas como mini batatas e tratadas por imersão em soluções antioxidantes de ácido cítrico a $2 \%$, ácido eritórbico a $3 \%$, combinação de ácido cítrico a $2 \%$ e ácido eritórbico a $3 \%$, e combinação de ácido cítrico a $3 \%$ e ácido eritórbico a 5\% embaladas em filmes de nylon multicamadas. Os três primeiros tratamentos foram embalados sob atmosfera modificada passiva enquanto no último tratamento aplicou-se atmosfera modificada ativa com $10 \% \mathrm{CO}_{2}, 2 \% \mathrm{O}_{2}, 88 \% \mathrm{~N}_{2}$. Observou-se que o tratamento com aplicação de antioxidantes em associação com atmosfera modificada ativa apresentou índice de escurecimento $24 \%$ menor e atividade enzimática da PPO e da POD $92 \%$ e $73 \%$ menor, respectivamente, que a média dos demais tratamentos no nono dia de observação. Houve elevação nos teores de vitamina $\mathrm{C}$ total, observado principalmente em tratamentos que utilizaram ácido eritrórbico. Observou-se uma correlação entre a degradação do amido e o aumento nos teores de açúcares solúveis totais e da vitamina $\mathrm{C}$ total em alguns tratamentos. $\mathrm{O}$ tratamento com aplicação de antioxidantes em associação com atmosfera modificada ativa foi o mais efetivo na manutenção dos atributos de qualidade de batatas minimamente processadas.
\end{abstract}

Palavras-chave: Solanum tuberosum L., processamento mínimo, alterações metabólicas.

\begin{abstract}
Association of modified atmospheres and antioxidants reduce browning of minimally processed potatoes

Enzymatic browning of minimally processed potatoes reduces the final price of the product. The present work was carried out aiming to evaluate chemical and physical characteristics in fresh-cut 'Ágata' potatoes stored under modified atmospheres and treated with antioxidants. Potatoes 'Ágata' were minimally processed as baby potatoes and treated with antioxidants solutions as follows: citric acid (2\%), eritrorbic acid (3\%), combination of citric acid (2\%) and eritrorbic acid (3\%), and stored under passive modified atmosphere. A fourth treatment consisting of the combination of citric acid (3\%) and eritrorbic acid (5\%), in association with active modified atmosphere $\left(10 \% \mathrm{CO}_{2}, 2 \% \mathrm{O}_{2}, 88 \% \mathrm{~N}_{2}\right)$ was set up. Baby potatoes treated with citric acid (3\%) and eritrorbic acid (5\%), in association with active modified atmosphere, had a browning index that was $24 \%$ lower than the average of the other 3 treatments at the end of the experiment. Similarly, polyphenoloxidase and peroxidase activity were 92 and $73 \%$ lower, respectively, in the treatment where antioxidants and active modified atmosphere were combined than the average of the other three treatments at the ninth day of storage. There was an increase in total vitamin C content, mainly in treatments where eritrorbic acid was applied. Combination of antioxidants and active modified atmosphere showed the best maintenance of quality attributes for fresh-cut potatoes.
\end{abstract}

Keywords: Solanum tuberosum L., minimal processing, metabolic changes.

(Recebido para publicação em 17 de julho de 2004 e aceito em 30 de agosto de 2005)

U $\mathrm{m}$ dos desafios ao processamento mínimo de batatas é a suscetibilidade dos tubérculos ao escurecimento enzimático oriundo de reações catalisadas por enzimas sendo a polifenoloxidase (PPO) a mais importante. Tais reações ocorrem quando há ruptura da célula, embora possam também ocorrer no tecido intacto de frutas e hortaliças (ARAÚJO, 2003). Os fatores mais importantes na evolução da taxa do escurecimento enzimático provocado são a concentração de PPO ativa e de compostos fenólicos, o pH, a temperatura e o oxigênio disponível no tecido. $\mathrm{O}$ pH ótimo da $\mathrm{PPO}$ varia com a fonte da enzima e com o substrato. $\mathrm{Na}$ maioria dos casos situa-se entre 6 e 7 e seu ajuste para valores inferiores a 4 possibilita o controle do escurecimento enzimático, desde que se considerem os aspectos sensoriais do produto (LAURILA et al, 1998a, 1998b).

A peroxidase (POD) também pode causar o escurecimento em hortaliças minimamente processadas. A POD contém um grupo heme e está relacionada com processos de cicatrização como, por exemplo, a lignificação (CANTOS et al., 2002). Em condições ideais, batatas inteiras descascadas podem ser estocadas sem agentes inibidores de escurecimento por sete dias (AHVENAINEN et al., 1998), o que não é possível para batatas em fatias (LAURILA et al., 1998a). Vários méto- dos para prevenir o escurecimento enzimático podem ser aplicados em batatas. Muitos inibidores de escurecimento são conhecidos, mas apenas alguns são potencialmente alternativos ao uso de sulfito. Os sulfitos, apesar de possuírem diversas vantagens técnicas, provocam a corrosão de equipamentos, a diminuição do valor nutricional, a perda de firmeza e a formação de sabores e odores desagradáveis (off-flavors) nos produtos aos quais é aplicado. Adicionalmente, o uso de sulfitos está cada mais associado a diversos malefícios à saúde (MCEVILY et al., 1991).

Dentre os antioxidantes mais pesquisados destacam-se os ácidos cí- 


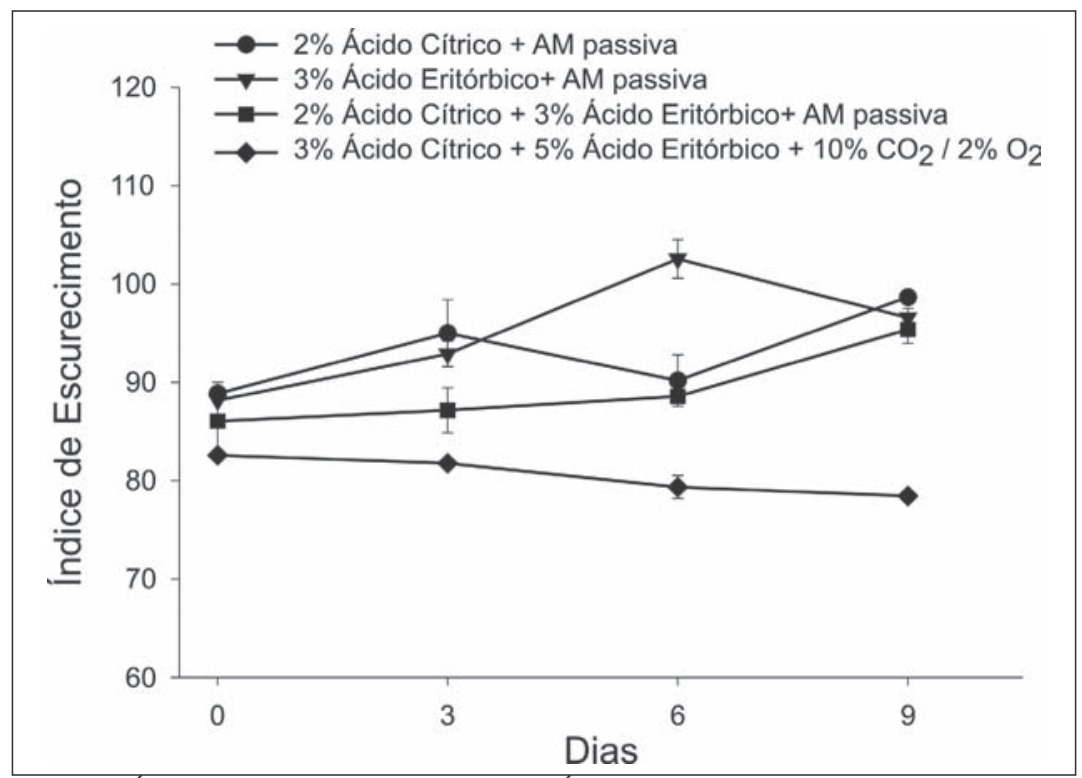

Figura 1. Índice de escurecimento de batatas 'Ágata' minimamente processadas armazenadas a $5^{\circ} \mathrm{C}$ com aplicação de antioxidantes e embalagem sob atmosfera modificada ativa e passiva. Embrapa Hortaliças, Brasília, DF, 2004. AM = atmosfera modificada. MF = Matéria fresca. Barras verticais representam o desvio-padrão da média. Brasília, Embrapa Hortaliças, 2004.

trico, ascórbico e eritrórbico. Sua acessibilidade no mercado, como ingredientes já em amplo uso na indústria alimentícia, aponta-os como opções para a indústria de batatas minimamente processadas. O custo do ácido eritrórbico, cinco vezes inferior ao de seu isômero, ácido ascórbico, justifica seu uso neste trabalho, de forma isolada ou em combinação com o ácido cítrico. A aplicação de atmosfera modificada ativa ou passiva, com baixas concentrações de $\mathrm{O}_{2} \mathrm{e}$ altas de $\mathrm{CO}_{2}$ também contribui para o controle do escurecimento e outros processos degradativos, uma vez que reduz a velocidade dos processos aeróbicos e implica baixa disponibilidade de $\mathrm{O}_{2}$ para a atividade da PPO.

Apesar da existência de diversos estudos enfocando o controle de escurecimento enzimático em produtos hortícolas, existe uma lacuna na literatura no que diz respeito à adoção de técnicas combinadas para redução dessa desordem em cultivares de hortaliças nacionais com potencial de aproveitamento para o processamento mínimo.

O objetivo deste trabalho foi caracterizar física e quimicamente batatas 'Ágata' minimamente processadas submetidas a diferentes tratamentos com antioxidantes e atmosfera modificada.

\section{Material vegetal}

Batatas (Solanum tuberosum L.) 'Ágata' da classificação "primeirinha" (diâmetro entre 40 e $60 \mathrm{~mm}$ ) foram adquiridas na Ceasa de Brasília, levadas ao Laboratório de Pós-Colheita da Embrapa Hortaliças, selecionadas, classificadas e lavadas em água potável;

\section{Processamento mínimo}

Tubérculos foram descascados por abrasão em máquina processadora (mosegundos em tambor revestido com lixa de 60 mesh e 36 segundos no segundo tambor revestido com lixa de 100 mesh. As batatas descascadas foram enxaguadas em água potável, sanitizadas em água com 150 ppm de cloro ativo por 5 minutos, imersas em soluções antioxidantes por 3 minutos e centrifugadas, por 7 minutos, a $800 \mathrm{~g}$.

Tratamento com antioxidantes

As soluções antioxidantes usadas foram $2 \%$ de ácido cítrico; $3 \%$ de ácido eritórbico; $2 \%$ de ácido cítrico $+3 \%$ de ácido eritórbico; e $5 \%$ de ácido eritórbico $+3 \%$ de ácido cítrico.

\section{MATERIAL E MÉTODOS} delo PCED, Siemsem Ltda.) por 180

\section{Embalagem e armazenamento}

O material foi posteriormente embalado em filme plástico de nylon multicamadas em seladora industrial (Selovac 200B, São Paulo, SP) em porções de 200 gramas, e armazenado sob refrigeração a $5^{\circ} \mathrm{C}$ por 9 dias. Os três primeiros tratamentos foram embalados sob atmosfera modificada passiva enquanto o último tratamento foi embalado sob atmosfera modificada ativa, pela utilização da mistura $10 \% \mathrm{CO}_{2}, 2 \% \mathrm{O}_{2}$, $88 \% \mathrm{~N}_{2}$.

\section{Análises químicas e físicas}

A cada 3 dias os tubérculos minimamente processados foram avaliados quanto às seguintes variáveis: Índice de escurecimento. $\mathrm{O}$ índice de escurecimento foi determinado por meio de um colorímetro Minolta Color Reader CR 200b (sistema L*a*b*), e calculado a partir da fórmula:

$$
\mathrm{IE}=[100(\mathrm{X}-0,31)] / 0,172 ; \mathrm{X}=(\mathrm{a}
$$
$+1,75 . \mathrm{L}) /(5,645 . \mathrm{L}+\mathrm{a}-3,021 . \mathrm{b})$

Atividade enzimática da polifenoloxidase e peroxidase. A atividade das enzimas polifenoloxidase e peroxidase foi determinada segundo o método descrito por Flurkey e Jen (1978), sendo o extrato lido a $395 \mathrm{~nm}$ para POP e a $470 \mathrm{~nm}$ para POD. Açúcares solúveis totais. Determinados pelo método fenol-sulfúrico descrito por Dubois et al. (1956). Teor de amido. Determinação feita a partir de adaptação realizada no método de Ranganna (1986), com extração de açúcares por solução de etanol (80\%) a quente, em 3 estágios, e hidrólise ácida do resíduo, também em 3 estágios, com ácido perclórico $(52 \%)$, com posterior determinação dos açúcares pelo método fenol-sulfúrico. Teor de vitamina $C$ total. A vitamina $\mathrm{C}$ total foi quantificada de acordo com metodologia descrita por Terada et al. (1978), modificado por Nunes et al. (1995).

O delineamento experimental foi inteiramente casualizado, com 16 tratamentos provenientes de um fatorial $4 \mathrm{x} 4$ (4 combinações de antioxidantes e 4 tempos de armazenagem), com 3 repetições. A unidade experimental considerada correspondeu a uma embalagem de 200 gramas. Os dados foram submetidos à análise de variância e as médias 
foram comparadas pelo teste da diferença mínima significativa $(\mathrm{p} \leq 0,05)$.

\section{RESULTADOS E DISCUSSÃO}

Índice de escurecimento (IE) $\mathrm{O}$ tratamento com ácido cítrico a $2 \%$ combinado com ácido eritrórbico a $3 \%$ apresentou melhor controle do escurecimento do que os tratamentos aplicados isoladamente até o terceiro dia de armazenamento (Figura 1). No nono dia, os IE dos tratamentos sob atmosfera modificada passiva estavam muito próximos e mostravam aumento do escurecimento das batatas de aproximadamente $10,5 \%$ em relação aos valores iniciais. $\mathrm{O}$ tratamento com atmosfera modificada ativa, em associação aos antioxidantes combinados, apresentou índice de escurecimento 6,2\% menor do que a média dos IE dos demais tratamentos logo após o processamento mínimo, indicando uma diferença significativa no controle do escurecimento nas primeiras horas após a injúria aos tubérculos. Não se observou elevação do IE para o tratamento sob atmosfera modificada ativa e ao final do experimento, verificou-se que o IE desse tratamento era aproximadamente $24 \%$ menor do que os demais tratamentos (Figura 1).

Diversos trabalhos avaliaram os efeitos das embalagens e de diferentes atmosferas no escurecimento de batatas minimamente processadas (GUNES; LEE, 1997; LAURILA et al., 1998a), e na composição nutricional (AHVENAINEN et al., 1998; TUDELA et al., 2002, 2003). Gunes \& Lee (1997) demonstraram que modificação ativa da atmosfera na embalagem foi necessária para estender a vida de prateleira de batatas, porém, a atmosfera modificada por si só não foi capaz de evitar o escurecimento. Os resultados confirmam a necessidade do tratamento por imersão com solução de agentes inibidores do escurecimento em batatas minimamente processadas. Quando se estudou a modificação da atmosfera, observou-se que a de $100 \% \mathrm{~N}_{2}$, em sacos de poliolefina multicamada, com alta permeabilidade, foi a mais eficaz.

Soluções de N-acetil-L-cisteína (1\%), ácido pentacético dietilenotriamina (DTPA) (1\%), e ácido eritrórbico (5\%)

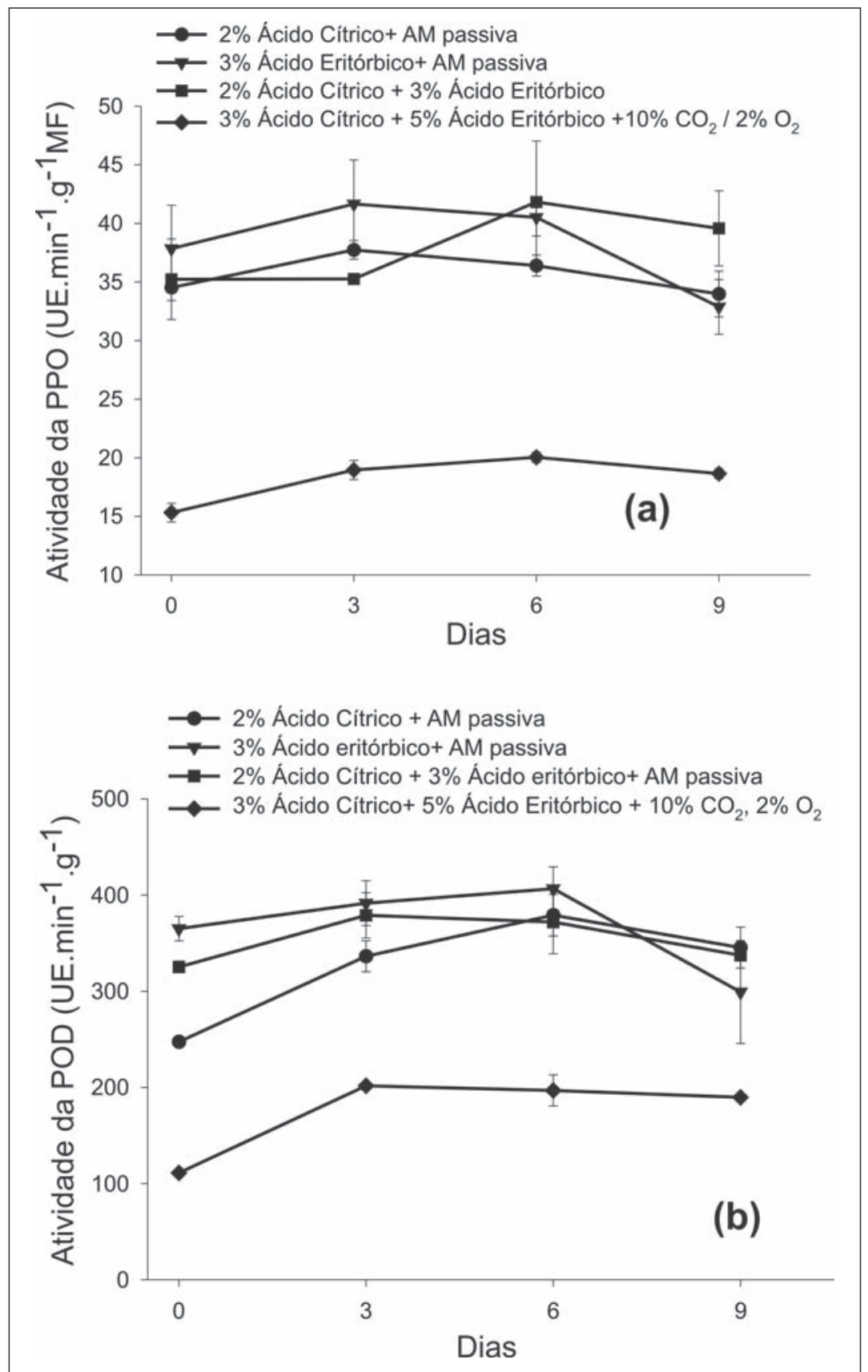

Figura 2. Atividade enzimática da polifenoloxidase (PPO) (a) e peroxidase (POD) (b) de batatas 'Ágata' minimamente processadas armazenadas a $5^{\circ} \mathrm{C}$ com aplicação de antioxidantes e embalagem sob atmosfera modificada ativa e passiva. Embrapa Hortaliças, Brasília, DF, 2004. $\mathrm{AM}=$ atmosfera modificada. $\mathrm{MF}=$ Matéria fresca. Barras verticais representam o desvio-padrão da média. Brasília, Embrapa Hortaliças, 2004.

+ ácido cítrico (1\%) usadas para tratamento de batatas em palitos, seguindose estocagem em atmosfera modificada a 1 e $6^{\circ} \mathrm{C}$, foram eficazes no retardamento do escurecimento enzimático. Os resultados obtidos no presente experimento para o tratamento com atmosfera mo- dificada ativa associada aos ácidos cítrico e eritrórbico estão em concordância com Cacace et al. (2002), que observaram que todos os tratamentos foram fortemente afetados pela temperatura de armazenamento. Segundo os autores, o tratamento com ácido cítrico e eritrórbico 


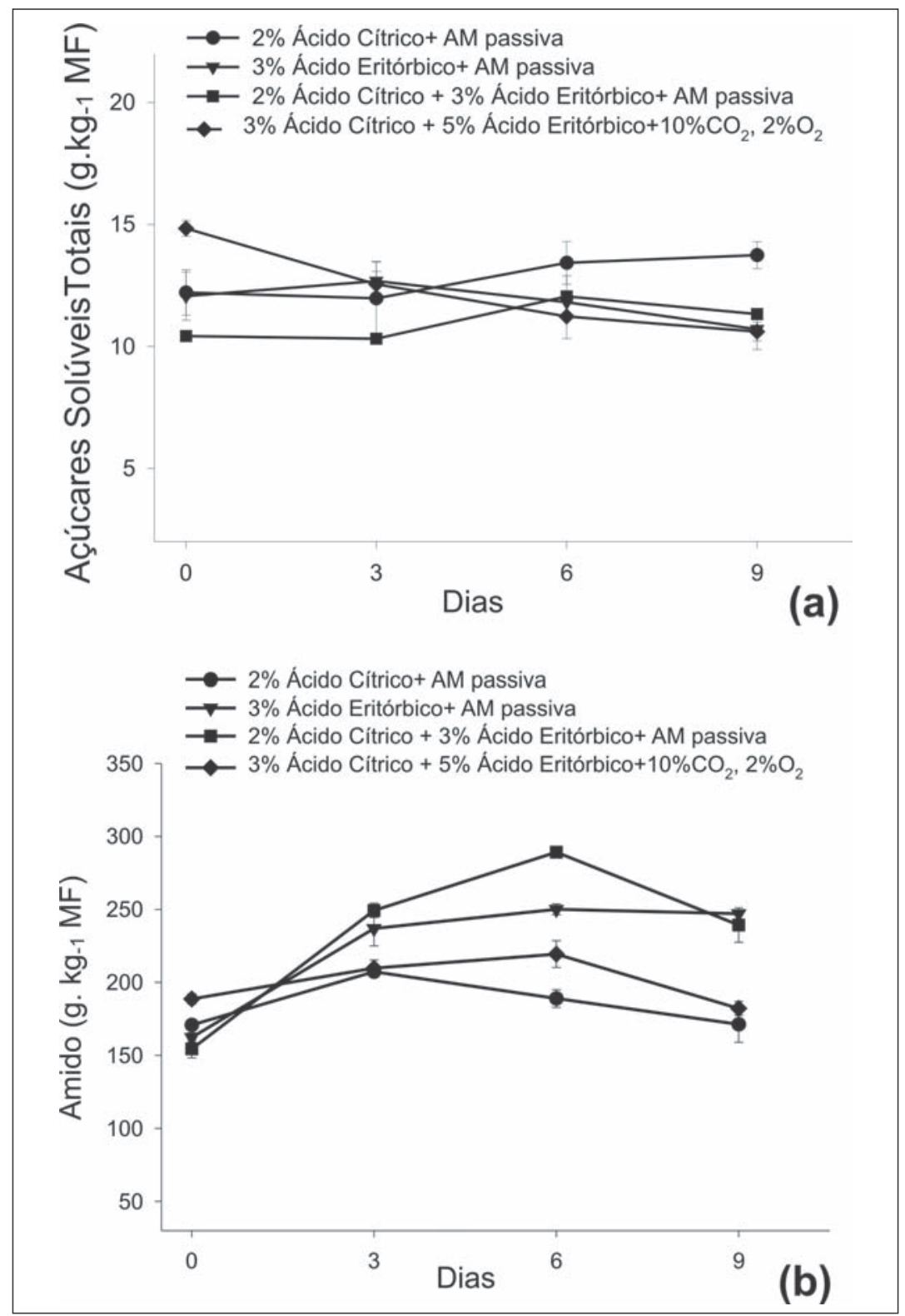

Figura 3: Teores de açúcares solúveis totais (a) e amido (b) de batatas 'Ágata' minimamente processadas armazenadas a $5^{\circ} \mathrm{C}$ com aplicação de antioxidantes e embalagem sob atmosfera modificada ativa e passiva. Embrapa Hortaliças, Brasília, DF, 2004. AM = atmosfera modificada. $\mathrm{MF}=$ Matéria fresca. Barras verticais representam o desvio-padrão da média. Brasília, Embrapa Hortaliças, 2004.

foi o único a ser comparado favoravelmente com batatas frescas preparadas, após 14 dias a $1^{\circ} \mathrm{C}$ ou 7 dias a $6^{\circ} \mathrm{C}$.

Atividade enzimática Não foi verificada diferença significativa na atividade da PPO para os tratamentos sob atmosfera modificada passiva logo após o processamento mínimo (Figura 2a). Os tratamentos armazenados sob atmosfera modificada passiva não apresentavam diferenças estatísticas quanto à ati- atmosfera modificada ativa foi o mais eficaz na inibição da atividade da PPO, que se apresentava 2,3 e 1,9 vezes menor do que a média dos demais tratamentos, no dia do processamento e após 9 dias de armazenamento, respectivamente (Figura 2a).

A atividade da POD no dia do processamento foi maior em batatas tratadas com 3\% de ácido eritrórbico (365,04 UE . $\left.\mathrm{g}^{-1} \mathrm{~min}^{-1}\right)$, e menor em batatas armazenadas sob atmosfera modificada ativa $\left(111,14 \mathrm{UE} \mathrm{g}^{-1} \mathrm{~min}^{-1}\right)(\mathrm{Fi}-$ gura $2 \mathrm{~b})$. $\mathrm{O}$ tratamento com $2 \%$ de ácido cítrico e o tratamento com $3 \%$ de ácido eritrórbico apresentaram aumento na atividade da POD até o sexto dia de armazenagem com posterior redução. Batatas tratadas com antioxidantes combinados em atmosfera modificada passiva ou ativa apresentaram controle da atividade da POD já a partir do terceiro dia (Figura 2b). Observou-se ainda, que a atividade da POD era 2,8 e 1,7 vezes menor no tratamento sob atmosfera ativa em relação à media dos demais tratamentos no dia do processamento e após 9 dias de armazenamento, respectivamente.

Cantos et al. (2002) avaliaram o efeito do processamento mínimo sobre a atividade das enzimas PPO, POD e fenilalanina amônia liase (PAL) e nos compostos fenólicos, em cinco cultivares de batatas. Não encontraram correlação significativa entre o grau ou taxa de escurecimento e quaisquer das variáveis investigadas. Entretanto, o aumento da atividade da POD, verificada pela síntese de isoperoxidases identificadas por eletroforese, confirmou a indução da atividade desta enzima como fenômeno comum no reino vegetal em resposta a situações de estresse, como injúrias mecânicas. Os autores sugerem que para melhor compreensão dos fatores limitantes do desenvolvimento do escurecimento em batatas minimamente processadas, estudos adicionais de outros aspectos importantes (estabilidade de membrana, composição lipídica, teor de cálcio, atividade de proteases, práticas agronômicas) são necessários. Semelhante ausência de correlação foi encontrada entre grau de escurecimento e atividade enzimática de maçãs durante o armazenamento a $0^{\circ} \mathrm{C}$ (COSETENG; LEE, 1987). 
Os resultados observados nas Figuras 1 e 2 mostram que o tratamento onde houve combinação de antioxidantes em atmosfera modificada ativa foi o mais eficaz no controle do escurecimento e da atividade das enzimas PPO e POD, o que se traduziu em manutenção da cor original do produto. A combinação dos antioxidantes ácidos pode ter contribuído para o abaixamento do $\mathrm{pH}$ do meio, reduzindo a atividade das enzimas associadas com o escurecimento enzimático. Esses resultados permitem inferir que tais tratamentos podem tornar viável a produção e comercialização de batatas minimamente processadas quando o aspecto visual é colocado em perspectiva.

Açúcares Solúveis Totais e Amido Batatas tratadas com $2 \%$ de ácido cítrico apresentaram, ao final de nove dias, aumento de $12,5 \%$ no conteúdo de açúcares solúveis totais, enquanto nos tubérculos tratados com $3 \%$ de ácido eritrórbico foi verificada uma redução de $12,7 \%$ no nono dia em comparação com os valores iniciais. Observou-se, ainda, em batatas tratadas com combinação de antioxidantes sob atmosfera modificada passiva um aumento de aproximadamente $17,0 \%$ no sexto dia, com subseqüente retorno aos patamares iniciais (Figura 3a).

A maior concentração de açúcares solúveis totais foi encontrada nas batatas armazenadas sob atmosfera modificada ativa, com valor inicial de $14,84 \mathrm{~g}$ $\mathrm{kg}^{-1} \mathrm{MF}$, que se reduziu, até o último dia de avaliação, em aproximadamente $40,0 \%$, igualando-se aos demais tratamentos. No nono dia de armazenamento observou-se que batatas tratadas com $2 \%$ de ácido cítrico possuíam o maior teor de açúcares solúveis totais, único que não sofreu imersão em ácido eritrórbico.

$\mathrm{O}$ teor de amido avaliado nas batatas minimamente processadas sofreu aumento ou manutenção de seus valores dependendo do tratamento em questão (Figura 3b). Segundo Borgstrom (1946), os teores de amido encontrados na matéria fresca de batata variam de 90 a 180 $\mathrm{g} \mathrm{kg}^{-1}$ MF sendo influenciados por variáveis como cultivar, época do ano, temperatura e tempo de armazenamento, entre outros (NOURIAN et al., 2003).

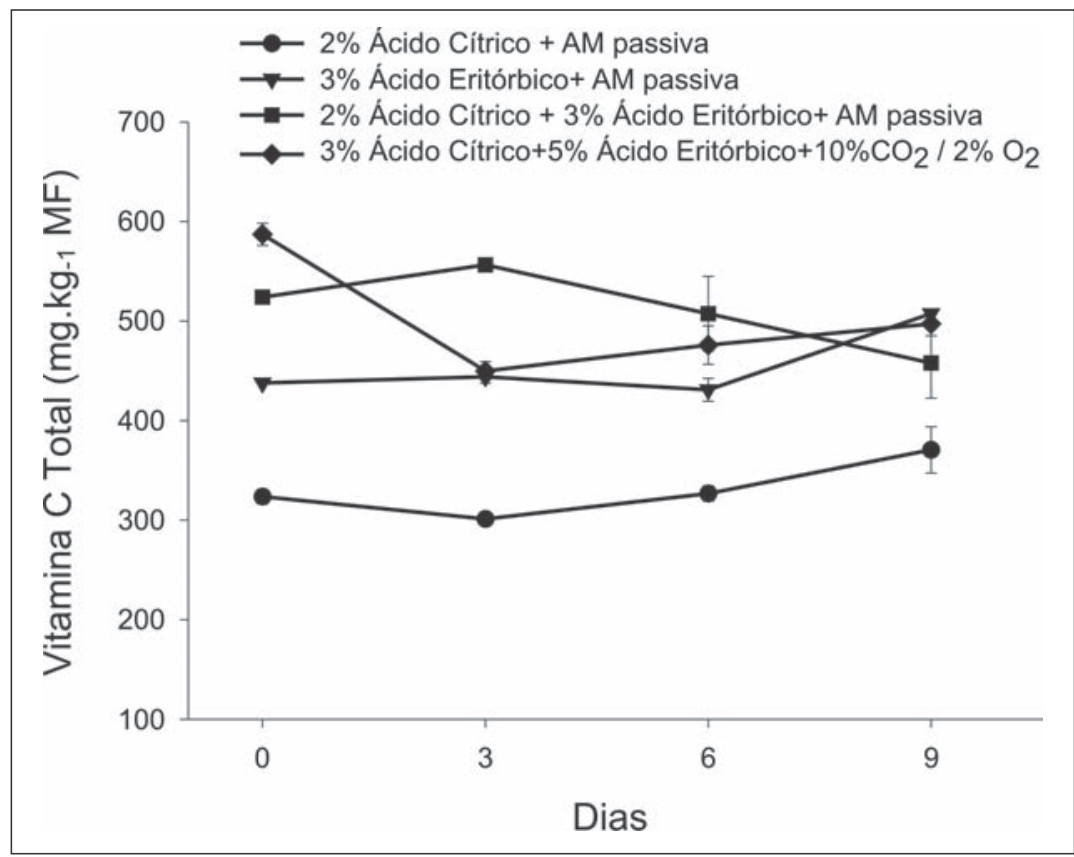

Figura 4. Vitamina $\mathrm{C}$ total de batatas 'Ágata' minimamente processadas armazenadas a $5^{\circ} \mathrm{C}$ com aplicação de antioxidantes e embalagem sob atmosfera modificada ativa e passiva. Embrapa Hortaliças, Brasília, DF, 2004. AM = atmosfera modificada. MF = Matéria fresca. Barras verticais representam o desvio-padrão da média. Brasília, Embrapa Hortaliças, 2004.

Os valores encontrados no dia do processamento são semelhantes aos valores citados pelo autor.

A conversão de amido em açúcares parece ser reversível (ISHERWOOD, 1973). Entretanto, o aumento nos teores de amido encontrados no presente experimento parece estar mais relacionado com a perda d'água sofrida pelos tubérculos, constatada pela umidade superficial crescente do produto após a centrifugação e durante o armazenamento. De acordo com Nourian et al. (2003), a degradação do amido ocorre rapidamente com a diminuição da temperatura, enquanto a variação dos açúcares totais e redutores está diretamente relacionada com o tempo de armazenamento. As condições de baixa temperatura resultam em acúmulo de ATP no tecido de batata e acarretam a ativação da via alternativa, conhecida como alternativa oxidse, que diminui os níveis de ATP e, simultaneamente, incrementa as concentrações de sacarose, provavelmente via fosforilase (ISHERWOOD, 1973). A sacarose torna-se o substrato da invertase ácida vacuolar, que originará o acúmulo de açúcares redutores (DUPLESSIS et al.,
1996). A indução do acúmulo de açúcares pelo frio estaria ainda relacionada com a deterioração das membranas dos amiloplastos (OHAD et al., 1971), favorecendo a ação da enzima amidofosforilase sobre o amido (FONTES; FINGER, 2000).

A inibição da conversão do amido em açúcares pela presença de $\mathrm{CO}_{2}$ já foi observada, assim como o aumento na síntese de amido e mudanças na atividade metabólica após a injúria aos tubérculos (SMITH, 1977). Isto poderia explicar, parcialmente, o maior teor de amido em batatas armazenadas sob atmosfera modificada ativa, com $10 \%$ de $\mathrm{CO}_{2}$ e $2 \%$ de $\mathrm{O}_{2}$ no dia do processamento, em comparação aos demais tratamentos, embalados sob atmosfera modificada passiva. De acordo com Pressey (1969), a atividade da sacarose sintetase, importante enzima envolvida na síntese do amido, é maior em tubérculos jovens de batata, em que se incluem fisiologicamente tubérculos da classificação "primeirinha". Apesar da provável distorção provocada pela perda de água, pode-se perceber um processo de degradação do amido nas batatas submetidas ao tratamento com $2 \%$ de áci- 
do cítrico, evidenciando após o terceiro dia uma degradação aparente de 21,0\%.

O tratamento sob atmosfera modificada ativa indicou redução nos teores de amido do sexto ao nono dia, com alteração de $20,7 \%$. Os demais tratamentos não apresentaram degradação de amido, mas estabilização ou acúmulo, podendo estar relacionado com ocorrência de maior perda d'água, ou menor degradação do amido nestas condições, de forma que não seja capaz de sobrepor o efeito da desidratação em nenhum dos tempos avaliados ou com processos de síntese de amido, conforme discutido.

A maior degradação do amido em batatas tratadas com ácido cítrico está em consonância com o crescimento do teor de açúcares solúveis totais verificado para este tratamento, sendo possível estabelecer correlações similares entre os resultados das Figuras $3 \mathrm{a}$ e $3 \mathrm{~b}$ para o tratamento com ácido eritrórbico $3 \%$. Batatas submetidas ao armazenamento sob atmosfera modificada ativa tiveram aumento no teor de amido até o sexto dia, a partir do qual se observou redução de $20,2 \%$ até o nono dia. Sugere-se para melhor avaliação desta variável a determinação do teor de amido sobre a matéria seca ao longo do armazenamento, ou, alternativamente, o acompanhamento da matéria seca do produto, ou determinação da perda d'água por métodos gravimétricos, o que possibilitaria uma associação com os resultados indicados na Figura 3b.

\section{Vitamina C Total}

$\mathrm{O}$ teor de vitamina $\mathrm{C}$ total também foi influenciado pela adição de antioxidantes aos tubérculos (Figura 4). $\mathrm{O}$ ácido eritrórbico é isômero do ácido ascórbico e pode ter causado alguma distorção na análise de vitamina $\mathrm{C}$ total. Observa-se que a curva com menor concentração de vitamina $\mathrm{C}$ total é a dos tubérculos tratados com $2 \%$ de ácido cítrico, única que não sofreu imersão em ácido eritrórbico. Além disso, a adição de antioxidantes pode prevenir a oxidação da vitamina $\mathrm{C}$ presente naturalmente na batata.

De acordo com Davey et al. (2000), batatas apresentam teores de vitamina $\mathrm{C}$ que variam entre 100 e $300 \mathrm{mg} \mathrm{kg}^{-1}$ MF. Estes valores podem variar de acor- do com a cultivar, com as práticas agrícolas, colheita e condições de armazenamento. $\mathrm{O}$ teor de vitamina $\mathrm{C}$ encontrado neste experimento em batatas intactas da cultivar Ágata, classificação "primeirinha", foi de 220,9 mg kg-1 $\mathrm{MF}$, dentro do intervalo proposto pelo autor. Os valores encontrados em batatas minimamente processadas, tratadas com antioxidantes, situaram-se acima deste intervalo.

Verificou-se que no dia do processamento todos os tratamentos diferiam entre si, sendo que batatas armazenadas sob atmosfera modificada ativa apresentavam o maior teor de vitamina $\mathrm{C}\left(587,14 \mathrm{mg} \mathrm{Kg}^{-1} \mathrm{MF}\right)$, seguindo-se o tratamento com combinação de antioxidantes armazenado sob atmosfera passiva $\left(524,07 \mathrm{mg} \mathrm{kg}^{-1} \mathrm{MF}\right)$, tratamento com $3 \%$ de ácido eritrórbico (437,76 $\left.\mathrm{mg} \mathrm{kg}^{-1} \mathrm{MF}\right)$ e $2 \%$ de ácido cítrico $\left(323,55 \mathrm{mg} \mathrm{kg}^{-1} \mathrm{MF}\right)$. Batatas tratadas com a combinação de antioxidantes e armazenadas sob atmosfera modificada ativa sofreram redução nos teores de vitamina $\mathrm{C}$ total ao terceiro dia de armazenamento, com posterior acúmulo até o nono dia. Os tratamentos com antioxidantes isolados, $2 \%$ de ácido cítrico e $3 \%$ de ácido eritrórbico, também apresentaram acúmulo de vitamina $\mathrm{C}$ com o tempo, com aumento de até $16,0 \%$ em seus teores (Figura 4). O tratamento onde se combinou os antioxidantes sob atmosfera modificada passiva foi o único que apresentou diminuição da vitamina $\mathrm{C}$ total $(14,5 \%)$, mas ainda assim permaneceu com valor 2,3 vezes superior ao das batatas intactas.

Batatas minimamente processadas são capazes de reter, total ou parcialmente, seu teor inicial de vitamina $\mathrm{C}$, considerando que as perdas decorrentes de processos de oxidação são compensadas pelo aumento na biossíntese de ácido ascórbico (TUDELA et al., 2002). Esse aumento pode estar correlacionado com a maior atividade da enzima Lgalactono-g-lactona dehidrogenase (GLDH) em tecidos de batata injuriados, a qual catalisa o passo final da biossíntese de ácido ascórbico (OBA et al., 1994) e poderia ser resultado da maior necessidade de poder antioxidante em nível celular para fazer frente ao estresse provocado pelo processamento mínimo (TUDELA et al., 2003). Além disso, o aumento da atividade respiratória provocado pelo processamento mínimo leva à degradação do amido, com acúmulo de glicose, substrato requerido no processo de síntese de ascorbato (NOCTOR; FOYER, 1998).

Prasanna et al. (2000) observaram que o pico respiratório ou climatérico em maçãs durante o amadurecimento coincide com seu teor máximo de ácido ascórbico, o que reforça uma possível correlação entre degradação do amido, aumento dos açúcares totais e síntese de ascorbato. Comportamento semelhante foi observado para tubérculos tratados com $2 \%$ de ácido cítrico, que a partir do terceiro dia de armazenamento apresentou redução nos teores de amido e aumento nos teores de açúcares solúveis totais e na vitamina $\mathrm{C}$ total, simultaneamente (Figuras 3 e 4).

$\mathrm{O}$ teor de vitamina $\mathrm{C}$ em um alimento deve incluir os teores de ácido ascórbico e deidroascórbico, uma vez esta última forma pode ser facilmente convertida na primeira no organismo humano. $\mathrm{O}$ ácido deidroascórbico pode ser oxidado irreversivelmente a ácido dicetogulônico, sem qualquer atividade de vitamina C (PARVIAINEN; NYYSSONEN, 1992), o que significaria na prática a perda de valor nutricional. A oxidação do ascorbato pela ascorbato oxidase aumenta em condições de estresse, exposição a patógenos, altas temperaturas, íons metálicos e agentes químicos (LEE; KADER, 2000). Portanto, o teor de vitamina $\mathrm{C}$ em batatas minimamente processadas é resultante de processos biossintéticos e degradativos que ocorrem simultaneamente.

No estudo apresentado, deve-se considerar a possibilidade da ocorrência de síntese de ascorbato em resposta ao estresse oxidativo e ao efeito da aplicação de antioxidantes na determinação da vitamina $\mathrm{C}$ total. Vale ressaltar que o método empregado para análise desta variável refere-se a materiais com teores baixos de vitamina $\mathrm{C}(50-400 \mathrm{mg}$ $\mathrm{kg}^{-1} \mathrm{MF}$ ), não sendo adequado para fontes mais ricas do nutriente. Como alguns tratamentos ultrapassaram os valores recomendados, outros métodos devem 
ser utilizados para confirmação dos resultados mais elevados. A utilização da técnica de cromatrografia líquida de alto eficiência (TUDELA et al., 2002) para determinação de ácido ascórbico e ácido deidroascórbico seria interessante para elucidação das possíveis interferências causadas pelos antioxidantes e para acompanhamento mais rigoroso dos processos biossintéticos e degradativos que envolvem o ascorbato nos tubérculos de batata. Tudela et al. (2003) estudaram o efeito do processamento mínimo, com subseqüente armazenamento sob refrigeração, $\mathrm{a} 4^{\circ} \mathrm{C}$, de batatas da cultivar Manon, sob diferentes atmosferas (ar, ar $+20 \%$ de $\mathrm{CO}_{2}$, $100 \% \mathrm{~N}_{2}$, e embalagem a vácuo), na atividade da enzima L-galactono- g-lactona dehidrogenase e no teor de Vitamina C. A embalagem a vácuo provou ser a melhor condição de embalagem, tendo evitado o escurecimento e retido $89,0 \%$ da Vitamina $\mathrm{C}$, seguido das atmosferas $100 \% \mathrm{~N}_{2}$ (78,0\% retenção) e $20 \% \mathrm{CO}_{2}+\operatorname{ar}(63,0 \%$ de retenção).

Em outra série de experimentos conduzida com batatas 'Ágata' e 'Monalisa' minimamente processadas sob vácuo parcial e diferentes temperaturas de armazenamento (dados não publicados), verificou-se a eficácia deste tipo de embalagem na retenção da vitamina $\mathrm{C}$, tendo sido observado acúmulo entre 49,0 e $58,4 \%$ deste nutriente ao fim dos nove dias de avaliação. Todavia, a perda de firmeza, o encharcamento da embalagem e o desenvolvimento de processos anaeróbios levando a odores desagradáveis comprometeram a aceitação do produto, o que levou à rejeição da utilização de vácuo nas embalagens.

\section{AGRADECIMENTOS}

Os autores agradecem o apoio financeiro recebido do projeto PRODETAB (ACORDO BIRD / EMBRAPA - Projeto 019) e à ADF Agropecuária do Distrito Federal.

\section{LITERATURA CITADA}

AHVENAINEN, R.T.; HURME. E.U., HÄGG M.; SKYTTÄ, E.H., LAURILA. E.K. Shelf life of pre-peeled potato cultivated, stored, processed by various methods. Journal of Food Protection, v.61, p.591-600, 1998.
ARAÚJO, J.M. Química de Alimentos - Teoria e Prática 3ª.edição. Viçosa: Editora UFV, 2003. BORGSTROM, G. Principles of Food Science $2^{\mathrm{a}}$. ed. Connecticut: Food and Nutrition Press, 1946. CACACE, J.E.; DELAQUIS, P.J.; MAZZA, G. Effect of chemical inhibitors and storage temperature on the quality of fresh-cut potatoes $J$. Food Quality, v.25, n.3, p.181-196, 2002.

CANTOS, E.; TUDELA, J.A.; GIL, M.I.; ESPÍN, J.C. Phenolic compounds and related enzymes are not rate-limiting in browning development of fresh-cut potatoes. J. Agric. Food Chem., v.50, p.3015-3023, 2002.

COSETENG, M.Y.; LEE, C.Y. Changes in apple polypnehnoloxidase and polyphenol concentrations in relation to degree of browning. J. Food Science, v.52, n.4, p.985-989, 1987.

DAVEY, M.W.; MONTAGU, M.V.; INZÉ, D.; SANMARTIM, M.; KANELLIS, A.; SMIRNOFF, N.; BENZIE, I.J.J.; STRAIN, J.J.; FAVEL, D.; FLETCHER, J. Plant ascorbic acid: chemistry, function, metabolism, bioavailability and effects of processing. J. Sci. Food Agric., v.80, p. 825-860, 2000.

DUBOIS, M.; GILLES, K.A.; HAMILTON, J.K.; REBERS, P.A. \& SMITH, F. Colorimetric method for determination of sugars and related substances. Anal. Chem. v. 28, p.350-356, 1956.

DUPLESSIS, P.M.; MARANGONI, A.G.; YADA, R.Y. A mechanism for low temperature induced sugar accumulation in stored potato tubers: the potential role of alternative pathway and invertase. American Potato Journal, v.73, p.97-100, 1996.

FLURKEY, W.H.; JEN, J. Peroxidase and polyphenoloxidase activities in developing peaches. J. Food Science, v.43, p.1826-1828, 1978.

FONTES, P.C.R.; FINGER, F.L. Pós-colheita do tubérculo de batata. $1^{\mathrm{a}}$. ed. Viçosa: Editora UFV, 2000, $46 \mathrm{p}$.

GUNES, G.; LEE, C.Y. Colour of minimally processed potatoes as affected by modified atmosphere and ant browning agents. J. Food Science, v.62, p.572-575,582, 1997.

ISHERWOOD, F.A. Starch-sugar interconversion in Solanum tuberosum. Phytochemistry, v.12, p.2579-2591, 1973.

LAURILA, E.; HURME, E.; AHVENAINEN, R. The shelf life of sliced raw potatoes of various cultivar varieties-substitution of bisulfites. J. Food Protection, v.61, n.10, p.1363-1386, 1998a.

LAURILA, E.; KERVINEN, R.; AHVENAINEN, $R$. The inhibition of enzymatic browning in minimally processed vegetables and fruits. Review article. Post Harvest News and Information. (1998b). Disponível em 〈http:// hort.cabweb.org〉 Acesso em: 10 jun. 2003.

LEE, S.K.; KADER, A.A. Preharvest and Postharvest factors influencing vitamin $\mathrm{C}$ content of horticultural crops. Postharvest Biology and Technology, v.20, p.207-220, 2000

MCEVILY, A.J.; Iyengar, R.; Otwell, W.S. Sulfite alternative prevents shrimp melanosis. Food Technology, v.45, p.80-86, 1991
NOCTOR, G; FOYER, CH. Ascorbate and glutathione: keeping active oxygen under control. Annu. Rev. Plant. Physiol. Mol. Biol., v.49, p.249279, 1998.

NOURIAN, F; RAMASWAMY, HS; KUSHALAPPA, AC. Kinetics of quality change associated with potatoes stored at different temperatures. Lebensm.-Wiss. U.-Technol., v.36, p.49-65, 2003.

NUNES, M.C.N.; BRECHT, J.K.; MORAIS, A.M.M.B.; SARGENT, S.A. Physical and chemical quality characteristics of strawberries after storage are reduced by a short delay to cooking. Postharvest Biology and Technology, v.6, p.17-28, 1995.

OBA, K. FUKUI, M.; IMAI, Y.; IRYAMA, S.; NOGAMI, K. L-Galactono- $;-$ lactone dehydrogenase: partial characterization, induction of activity and role in the synthesis of ascorbic acid in wounded white potato tuber tissue. Plant Cell. Physiology, v.35, p.473-478, 1994.

OHAD, I.; FRIEDBERG, I.; NEMAN, Z.; SCRAMM, M. Biogenesis and degradation of starch. the fate of amyloplast membrane during maturation and storage of potato tubers. Plant Physiology, v.47, p.465-477, 1971.

PARVIAINEN, M.T.; NYYSSONEM, K. Ascorbic acid. In: LEENHEER, A.P.D; LAMBERT, W.E. NELIS, H (Eds) Modern Chromatografic Annalysis of Vitamins. New York: Marcel Dekker, 1992.

PRASANNA, K.N.V., RAO, D.V.S KRISHNAMURTHY, S., Effect of storage temperature on ripening and quality of custard apple (Annona squamosa L.) fruits. J. Hortic. Sci. Biotech., v.75, p.546-550, 2000

PRESSEY, R. Role of invertase in accumulation of sugars in cold-stored potatoes. American Potato Journal, v.46, p.291-297, 1969.

RANGANNA, S. Handbook of analysis and quality control for fruits and vegetables products. Tata Mcgraw Publishers, New Delhi, 1986, 107 p.

SMITH, O. Potatoes: production, storing, processing. 2a. edição. Westpot,:Avi. Publishing, 1977. 286 p.

TERADA, M.; WATANABE, Y.; KUNITOMA, M.; HAYASHI, E. Differential rapid analysis ascorbic acid and ascorbic acid 2-sulfate by dinitrophenilhydrazine method. Annals of Biochemistry, v.4, p.604-8, 1979

TUDELA, J.A.; ESPÍN, J.C.; GIL, M.I. Vitamin $\mathrm{C}$ retention in fresh-cut potatoes. Postharvest Biology and Technology, v.26, p.75-84, 2002.

TUDELA, J.A.; HERNÁNDEZ, J.A.; GIL, M.I.; ESPÍN, J.C. L-galactono-g- lactone dehydrogenase activity and vitamin $\mathrm{C}$ content in fresh-cut potatoes stored under controlled atmospheres. J. Agric. Food Chem., v.51, p.42964302, 2003. 